Article

\title{
Internalised Ageism and Self-Exclusion: Does Feeling Old and Health Pessimism Make Individuals Want to Retire Early?
}

\author{
Mariska van der Horst \\ Department of Sociology, Vrije Universiteit Amsterdam, 1081 HV Amsterdam, The Netherlands; \\ E-Mail:m.f.j.vanderhorst@vu.nl
}

Submitted: 10 December 2018 | Accepted: 12 April 2019 | Published: 29 July 2019

\begin{abstract}
An important current policy goal in many Western countries is for individuals to extend their working lives. Ageism has been identified as a possible threat to achieving this; furthermore, the ways in which ageism may affect this policy goal may have been underestimated. It has been claimed previously that ageism can be seen as discrimination against one's future self and that a lifetime of internalising age stereotypes makes older people themselves believe the age stereotypes. The current article uses the English Longitudinal Study of Ageing to assess the degree to which internalised ageism is related to one's preferred retirement age. For internalised ageism, assessments are made about the degree to which individuals consider themselves to be old; they agree that their age prevents them from undertaking activities; they are pessimistic about their own future health and that being old comes with deteriorating health more generally. Results show that health pessimism especially affects one's preferred retirement age negatively, even when controlling for current health and other factors, and mainly for middle-educated women. Implications are discussed.
\end{abstract}

\section{Keywords}

ageism; educational level; gender; health pessimism; internalised ageism; older worker; retirement; retirement age; stereotypes; UK

\section{Issue}

This article is part of the issue "Old-Age Exclusion", edited by Wouter De Tavernier (KU Leuven, Belgium) and Marja Aartsen (OsloMet-Oslo Metropolitan University, Norway).

(C) 2019 by the author; licensee Cogitatio (Lisbon, Portugal). This article is licensed under a Creative Commons Attribution 4.0 International License (CC BY).

\section{Introduction}

It has been claimed that workers need to extend their working lives, as increased population ageing will put pressure on the welfare state, lead to a larger dependency ratio (number of people considered to be dependent on employment-aged individuals), and therewith also (negatively) affect economic growth and productivity (cf. ILC-UK, 2017; Phillipson, 2018). Projections for the European Union have indicated that the percentage of people aged 65 and older will rise from $17 \%$ in 2010 to over $30 \%$ in 2060 (Walker \& Maltby, 2012). Although assumptions behind this have been challenged (see, e.g., Phillipson, 2018), extending workers' working lives remains an important policy goal in many Western countries (see, e.g., Egdell, Maclean, Reaside, \& Chen, 2018). Age discrimination has been identified as an important limitation to this policy goal, however (e.g., Loretto \& White, 2006; Walker \& Maltby, 2012; see also Posthuma \& Campion, 2009). There are now several experimental studies suggesting that-at least for certain jobs-employers prefer younger workers (e.g., Ahmed, Andersson, \& Hammarstedt, 2012; Riach \& Rich, 2002).

Though it is important to understand how employers may block the extending working agenda, ageism may have a greater impact than (conscious or unconscious) age discrimination. According to the stereotype embodiment theory (Levy, 2009), individuals internalise stereotypes about older people, which may affectamong other things - their expectations and behaviour. Although Levy (2009) focuses on health consequences, it is likely that the effects will go beyond health expectations and behaviour. There are some early indications that it may also impact on an individual's retirement 
expectations or preferences and behaviour, though research on this topic is scarce. For example, a recent qualitative study showed that some individuals appear to self-exclude from promotion opportunities, training, and paid work as a result of internalised ageism (Van der Horst, 2018). However, most research on internalised ageism of older workers and the possible consequences for retirement preferences, expectations or decisions are qualitative in nature, leading to questions about generalisability. Moreover, as will be explained, these relationships between internalised ageism and self-exclusion from the labour market will be different for subgroups of workers. This article will assess whether relationships are the same for men and women, and workers of various educational levels.

In the current article, I will quantitatively assess the relationship between internalised ageism and expected self-exclusion from the labour market in the English context. Age perception, health pessimism and the belief that (old) age limits activities are related to preferred retirement age using the English Longitudinal Study of Ageing (ELSA). A context-setting discussion of previous literature leads to an overview of the data and methods informing this study, followed by the results. These show that, when controlling for other factors such as actual health and finances, health pessimism appears to be (negatively) related to preferred retirement age, but mostly for middle-educated women. Finally, the article concludes by discussing the implications of these research findings.

\section{Theoretical Background}

\subsection{Ageism}

Ageism is defined as "a multi-dimensional concept, which incorporates ageist stereotypes (both positive and negative beliefs), prejudicial and stigmatising attitudes, and age-based discrimination" (Azulai, 2014, p. 3). Ageist stereotypes are in turn defined as a "simplified, undifferentiated portrayal of an age group that is often erroneous, unrepresentative of reality, and resistant to modification" (Schulz, Noelker, Rockwood, \& Sprott, 2006, p. 43). Both employers and employees have a combination of positive and negative stereotypes about older workers. For example, employers perceive older workers as less adaptable to change, but at the same time as more loyal (Egdell et al., 2018; Loretto \& White, 2006). Such stereotypes have been tested for accuracy and are usually found to not hold. For example, $\mathrm{Ng}$ and Feldman (2012, p. 821) assessed in a meta-analysis whether older workers are “(a) less motivated, (b) generally less willing to participate in training and career development, (c) more resistant and less willing to change, (d) less trusting, (e) less healthy, and (f) more vulnerable to workfamily imbalance". They only found some evidence that older workers were less willing to participate in training and career development, though this may partly be due to the internalisation of ageism and self-exclusion based on stereotypes (see Sections 2.2 and 2.3). Even though a persistent stereotype about older workers is that they would be less healthy (see also Grendon, Inker, \& Welleford, 2018), this was not supported by the meta-analysis.

\subsection{Internalised Ageism}

Individuals internalise stereotypes about older workers throughout their life course (Levy, 2009). When older, they actively distance themselves from being considered 'old' as they do not consider themselves to match the stereotypes (Minichiello, Browne, \& Kendig, 2000). When individuals are not able 'to keep up', they may see this as an individual failure and a logical consequence of being older rather than a social issue. When individuals self-identify as being older, they may change their behaviour accordingly. As also recognised by at least some employers, individuals may not go for training because they feel they are 'too old' (Loretto \& White, 2006). Internalised ageism has shown to have far-reaching consequences, such as worse health and well-being outcomes, and even an increased likelihood of (earlier) mortality (e.g., Levy, 2009; Swift, Abrams, Lamont, \& Drury, 2017).

In this article, several statements are assessed. First, to what degree do individuals consider themselves to be old. This is considered a general evaluation of oneself against an internalisation of all (positive and negative) images of what it means to be 'old' (on subjective age for a similar argument that the degree to which one 'feels old' is internalised ageism see also Grendon et al., 2018). Second, to what degree do individuals agree that their age prevents them from undertaking activities. This statement is typically used in the self-enumerated scale of quality of life (CASP-19) for the life domain 'control' (see, e.g., Wiggins, Netuveli, Hyde, Higgs, \& Blane, 2008). However, this statement can also be a manifestation of both age discrimination (individuals being blocked from certain activities due to their age) as well as considering oneself to be 'too old' for certain activities. Finally, an important age stereotype is that old age comes with reduced physical and mental health (see, e.g., Grendon et al., 2018). Therefore, the degree to which individuals are pessimistic about their own future health is assessed alongside whether they agree that being old comes with worse health more generally. This will be referred to more broadly as health pessimism (cf. Brown \& Vickerstaff, 2011). Because I control for actual health (as well as other factors) this is considered health pessimism rather than a reflection of current health.

\subsection{Self-Exclusion Based on Internalised Ageism}

According to the 'socioeconomics' perspective, social norms are 'enforced' through internalisation. Where the 'rational choice' perspective indicates that individuals will be sanctioned for violating certain norms, the 'socioeconomics' perspective indicates that individuals in- 
ternalise norms and use these to set their own goals (Radl, 2012; also see Etzioni, 2000). Hence, according to the 'rational choice' model, one may see individuals retire due to age discrimination while actually preferring to retire later, while according to the 'socioeconomics' perspective, individuals may themselves indicate that they want to retire earlier based on internalised norms (cf. Radl, 2012). When certain stereotypes (such as older people are in a reduced state of physical health) are considered a normal part of ageing, individuals will not challenge whether this is due to ageing and adapt their behaviour accordingly (see also the stereotype embodiment theory in Levy, 2009). For example, Minichiello et al. (2000) found in their (qualitative) paper that older people experiencing access issues considered this an individual problem that led individuals to disengage with certain activities, such as an individual who was having difficulty getting onto a bus stopped using it and considered this a logical consequence of getting older (Minichiello et al., 2000, pp. 262-263). In this article, I focus on retirement preferences. In relation to this, Maurer, Barbeite, Weiss and Lippstreu (2008) found that the (internalised) belief that older workers cannot and/or do not want to develop (anymore) was related to their retirement beliefs, that is, their belief that they "should retire due to a variety of reasons such as no longer being interested in changes, retirement just being most appropriate, no longer being interested in career", etc. (Maurer et al., 2008, p. 404).

The following hypotheses follow:

- H1a: Believing that age limits activities is negatively related to one's preferred retirement age.

- H1b: Perceiving oneself to be old is negatively related to one's preferred retirement age.

Van der Horst (2018) found in her qualitative UK study on internalised ageism and self-exclusion from the labour market that respondents had internalised the physical decline narrative of ageing. Pond, Stephens and Alpass (2010) speak in this respect about "maximisation of life": wanting to retire while still healthy in order to be able to fulfil other life goals "with the intention of maximising their enjoyment of their remaining years of good health" (Pond et al., 2010, p. 533). This seems to be at least partly based-according to their qualitative study in New Zealand-on the presumption of older age coming with worsened health (Pond et al., 2010). Brown and Vickerstaff (2011) refer to this as "health pessimism" and indicate that this may be an important factor as to why individuals exit paid work. Where Brown and Vickerstaff (2011) also discuss how the interplay between individual experiences and social structures affect health pessimism, the current article focuses on the consequences of health pessimism on retirement preferences:

- H2: Health pessimism is negatively related to one's preferred retirement age.

\subsection{Gender, Education, and Self-Exclusion Based on Internalised Ageism}

Social norms regarding what types of behaviours and attitudes are appropriate for older workers will not be uniform, instead differing between groups of workers. For example, research has demonstrated how gender and social class influence perceptions about when an individual should retire (Radl, 2012). Related to gender, Van der Horst, Lain, Vickerstaff, Clark and Geiger (2017) showed that gender roles affect older workers' employment patterns. The impact of gender roles, thus, is not limited to younger workers. O'Connor, Orloff and Shaver (1999) identified the UK as a "modified male breadwinner/female caregiver" society, with women working parttime while combining paid work with care responsibilities and men working full-time as main breadwinners. Loretto and Vickerstaff (2013) found that this affects the point at which women wanted to retire; gender roles had limited women to jobs with fewer opportunities, therefore retirement became an escape from a job they did not like. More directly related to the impact of internalised ageism on preferred retirement age: ageism is gendered (e.g., Jyrkinen \& McKie, 2012), women in the workplace are considered 'old' at younger ages than men (Duncan \& Loretto, 2004) and women are expected to retire at younger ages than men (Radl, 2012). This makes it likely that the way in which internalised ageism relates to self-exclusion from the labour market differs between men and women. Based on this, we would expect the relationships to be more pronounced among women than among men. However, it should be noted that not all studies found gender differences in experienced ageism (see, e.g., Palmore, 2001).

A second distinction made in this article is the educational level. It is known that individuals with a higher educational level are more likely to be employed at older ages (Bjursell, Nystedt, Björklund, \& Sternäng, 2017). Social norms regarding when an individual should retire are, however, also dependent on social class (Radl, 2012). This suggests that the ageism that individuals will experience and internalise is likely to depend on social class and educational level, with age norms mattering less for individuals with higher levels of education. Palmore (2001) found that individuals with less education appeared to experience more ageism than individuals with more education. Based on this, we may expect that the consequences of ageism may be more pronounced for lesser educated individuals. However, people with lower levels of education may be more dependent on their state pension and may not have the financial option to stop working earlier regardless of whether or not they want to be in employment (Lain, Van der Horst, \& Vickerstaff, in press). Hence, patterns may be clearest among middleeducational level respondents who may have more options available concerning when to retire and experience more ageism than higher educated individuals. 


\section{Data}

This article considered wave $7(2014 / 2015)$ and 8 (2016/2017) of ELSA (Marmot et al., 2018). Earlier waves are excluded as the (internalised) ageism variables are not frequently asked in ELSA. As the situation in 2004/2005 (wave 2; last time all used questions were included) may have been very different (e.g., before the recent economic crisis of 2009), I focussed on the last two waves only. I selected core members (also excluding proxy interviews) aged 50 to 70 in wave 7 . I also only included employed individuals in wave 7. For employment status, respondents could indicate which of a list best described their current situation. Respondents were then asked which activities they performed. The options respondents could choose from included paid work and self-employment (individuals in self-employment were excluded). If they indicated they did neither, they were asked whether they were temporarily away from work, looking for work, or waiting for work that had already been accepted. If the respondent indicated they were temporarily away from work or waiting for work that had already been accepted, they are considered as being employed. Based on the selections made, and excluding missing data, 1,067 respondents were left, of whom $53 \%$ were female. The consequences of listwise deletion of missing data are assessed in a robustness check.

\section{Variables}

In this article, one's preferred retirement age was used as a dependent variable. In the self-completion questionnaire, respondents were asked: "At what age would you like to retire?"

Preferred retirement age is reasonably related to actual retirement and considered a better predictor of actual retirement ages than whether respondents are considering working after pension eligibility ages (Solem et al., 2016). Individuals could write in their desired retirement age or tick a box stating that they were already retired. For individuals writing in an age, individuals used ages anywhere between 0 and 120 . However, less than $1 \%$ mentioned an age younger than 50 and less than $2 \%$ mentioned an age older than $90 . \mathrm{I}$, therefore, recoded all ages mentioned younger than 50 to 50 and older than 90 as 90 and assessed the consequence of doing so in a robustness check.

The main independent variables are three types of age perceptions. For $\mathrm{H} 1 \mathrm{a}$, whether the respondent believes age limits activities is measured with the statement "My age prevents me from doing the things I would like to do", with answering options (1) often, (2) sometimes, (3) not often, and (4) never. This is reversed coded so that a higher score means more often perceiving that age prevents respondents from doing things they want to do. This variable is referred to as age prevents.

For H1b, whether the respondent considers him/herself to be old is measured with the statement "I don't think of myself as old", with answering categories running from (1) strongly agree to (5) strongly disagree. Therefore, the higher the score, the more the respondents perceive themselves as being old. This variable is referred to as thinks old.

For $\mathrm{H} 2$, health pessimism is measured with two statements, "Old age is a time of ill health" and "I worry that my health will get worse as I grow older", both having the same answering categories as the previous variable. These variables were reverse coded so that a higher score meant more health pessimism. Although individuals may think about different ages when considering these health pessimism statements, this should not matter for the interpretation of the results if a relationship is found; the expectation that health will get worse (regardless of the age the respondent is thinking about) still affects current retirement preferences. "Old age is a time of ill health" is referred to as old bad health and "I worry that my health will get worse as I grow older" as worry old health.

The analyses are controlled for an individual's age (in years), self-reported health (5-point scale), whether the respondent has any long-standing illness, disability or infirmity (yes/no) and if so whether these limit activities (yes/no), which income quartile the respondent belongs to (based on the equivalised version of the total benefit unit income), whether the respondent works fulltime (yes/no), and the respondent's educational level (no qualification/foreign/other = low; nvq 1-3 = middle; higher education below degree, or nvq 4-5 = high), and sex (female versus male).

Descriptive statistics are shown in Table 1. Here one can see that the preferred retirement age is about 65 years old in wave 8 . Women prefer to retire about a year earlier than men and preferred retirement age is highest among lowest educated individuals, with smaller differences between middle and higher-educated individuals.

\section{Method}

OLS regression analyses are performed for the respondent's preferred retirement age in wave 8 , given their age perceptions in wave 7 , the benefit being that the independent variables are measured before the outcome variable. By using predictors from wave 7 and an outcome variable in wave 8 it is hoped that there is less of a case that causality may be reversed. In both cases, the analyses are done without control variables first, and then with control variables. Analyses are done on the full sample, men and women separately, and different educational levels separately. In the web appendix, one can find the analyses for preferred retirement age in wave 7 . This is to check whether the time between the waves may be too long ( 2 years) to observe certain associations. All analyses make use of the bias-corrected and accelerated bootstrap confidence intervals that correct for bias and skewness in the data (Puth, Neuhäuser, \& Ruxton, 2015). Analyses are performed on 5000 bootstrapped samples. All analyses are performed in Stata 15 (Statacorp, 2017). 
Table 1. Descriptives

\begin{tabular}{|c|c|c|c|c|c|c|c|c|c|c|c|c|c|c|c|c|c|c|}
\hline \multirow[b]{2}{*}{ Variables } & \multicolumn{3}{|c|}{ Total sample } & \multicolumn{3}{|c|}{ Men only } & \multicolumn{3}{|c|}{ Women only } & \multicolumn{3}{|c|}{ Low education only } & \multicolumn{3}{|c|}{ Middle education only } & \multicolumn{3}{|c|}{ High education only } \\
\hline & Mean & $S D$ & Range & Mean & $S D$ & Range & Mean & $S D$ & Range & Mean & $S D$ & Range & Mean & $S D$ & Range & Mean & $S D$ & Range \\
\hline Preferred retirement age w.7 & 63.94 & 4.74 & $50-90$ & 64.59 & 4.83 & $50-90$ & 63.38 & 4.59 & $50-90$ & 64.64 & 5.32 & $50-90$ & 63.67 & 4.27 & $50-90$ & 63.71 & 5.80 & $50-90$ \\
\hline Preferred retirement age w. 8 & 65.07 & 5.75 & $50-90$ & 65.71 & 5.75 & $50-90$ & 64.48 & 5.69 & $50-90$ & 66.07 & 6.75 & $50-90$ & 64.45 & 4.79 & $55-90$ & 64.98 & 5.80 & $50-90$ \\
\hline \multicolumn{19}{|l|}{ Explanatory variables $w .7$} \\
\hline Thinks old & 1.88 & 1.07 & $1-5$ & 1.93 & 1.02 & $1-5$ & 1.83 & 1.10 & $1-5$ & 1.85 & 1.09 & $1-5$ & 1.99 & 1.13 & $1-5$ & 1.77 & 0.95 & $1-5$ \\
\hline Old bad health & 2.19 & 1.09 & $0-4$ & 2.29 & 1.05 & $0-4$ & 2.11 & 1.12 & $0-4$ & 2.22 & 1.11 & $0-4$ & 2.09 & 1.10 & $0-4$ & 2.27 & 1.06 & $0-4$ \\
\hline Worry old health & 2.72 & 0.96 & $0-4$ & 2.67 & 0.97 & $0-4$ & 2.77 & 0.95 & $0-4$ & 2.71 & 0.96 & $0-4$ & 2.67 & 0.99 & $0-4$ & 2.80 & 0.93 & $0-4$ \\
\hline Age prevents & 1.92 & 0.82 & $1-4$ & 1.97 & 0.81 & $1-4$ & 1.88 & 0.83 & $1-4$ & 2.01 & 0.84 & $1-4$ & 1.93 & 0.84 & $1-4$ & 1.85 & 0.78 & $1-4$ \\
\hline \multicolumn{19}{|l|}{ Control variables w.7 } \\
\hline Self-rated health & 3.54 & 0.98 & $1-5$ & 3.55 & 0.97 & $1-5$ & 3.53 & 0.98 & $1-5$ & 3.36 & 0.93 & $1-5$ & 3.49 & 1.00 & $1-5$ & 3.73 & 0.94 & $1-5$ \\
\hline \multicolumn{19}{|l|}{ Serious illness } \\
\hline No illness & 0.44 & - & Ref & 0.48 & - & Ref & 0.41 & - & Ref & 0.39 & - & Ref & 0.39 & - & Ref & 0.52 & - & Ref \\
\hline Illness & 0.39 & - & $0-1$ & 0.38 & - & $0-1$ & 0.40 & - & $0-1$ & 0.43 & - & $0-1$ & 0.41 & - & $0-1$ & 0.35 & - & $0-1$ \\
\hline Activity limiting illness & 0.17 & - & $0-1$ & 0.14 & - & $0-1$ & 0.19 & - & $0-1$ & 0.18 & - & $0-1$ & 0.20 & - & $0-1$ & 0.13 & - & $0-1$ \\
\hline \multicolumn{19}{|l|}{ Income level } \\
\hline Income quartile 1 (lowest) & 0.13 & - & Ref & 0.09 & - & Ref & 0.16 & - & Ref & 0.16 & - & Ref & 0.15 & - & Ref & 0.07 & - & Ref \\
\hline Income quartile 2 & 0.21 & - & $0-1$ & 0.19 & - & $0-1$ & 0.23 & - & $0-1$ & 0.25 & - & $0-1$ & 0.24 & - & $0-1$ & 0.15 & - & $0-1$ \\
\hline Income quartile 3 & 0.31 & - & $0-1$ & 0.33 & - & $0-1$ & 0.29 & - & $0-1$ & 0.31 & - & $0-1$ & 0.34 & - & $0-1$ & 0.27 & - & $0-1$ \\
\hline Income quartile 4 (highest) & 0.36 & - & $0-1$ & 0.39 & - & $0-1$ & 0.32 & - & $0-1$ & 0.28 & - & $0-1$ & 0.27 & - & $0-1$ & 0.51 & - & $0-1$ \\
\hline Fulltime job (vs. part-time) & 0.60 & - & $0-1$ & 0.82 & - & $0-1$ & 0.40 & - & $0-1$ & 0.61 & - & $0-1$ & 0.54 & - & $0-1$ & 0.67 & - & $0-1$ \\
\hline Age & 59.18 & 4.53 & $50-70$ & 59.55 & 4.54 & $50-70$ & 58.86 & 4.50 & $50-70$ & 60.14 & 4.49 & $50-70$ & 58.51 & 4.61 & $50-69$ & 59.19 & 4.34 & $51-70$ \\
\hline Female (vs. male) & 0.53 & - & $0-1$ & 0 & 0 & 0 & 1 & 1 & 1 & 0.54 & - & $0-1$ & 0.62 & - & $0-1$ & 0.43 & - & $0-1$ \\
\hline \multicolumn{19}{|l|}{ Educational level } \\
\hline Low education & 0.27 & - & Ref & 0.27 & - & Ref & 0.27 & - & Ref & 1 & 1 & 1 & 0 & 0 & 0 & 0 & 0 & 0 \\
\hline Middle education & 0.39 & - & $0-1$ & 0.31 & - & $0-1$ & 0.45 & - & $0-1$ & 0 & 0 & 0 & 1 & 1 & 1 & 0 & 0 & 0 \\
\hline High education & 0.34 & - & $0-1$ & 0.42 & - & $0-1$ & 0.28 & - & $0-1$ & 0 & 0 & 0 & 0 & 0 & 0 & 1 & 1 & 1 \\
\hline $\mathrm{N}_{\text {all variables wave } 7}$ & 1,067 & & & 497 & & & & 570 & & 284 & & & 415 & & & 368 & & \\
\hline $\mathrm{N}_{\text {expected retirement wave } 8}$ & 722 & & & 347 & & & & 375 & & 197 & & & 280 & & & 245 & & \\
\hline
\end{tabular}




\section{Results}

\subsection{Without Controls}

Table 2 shows the relationships between the main independent variables and preferred retirement age two years later. The most consistent relationship appears to be between health pessimism and preferred retirement age (in support for $\mathrm{H} 2$ ). When individuals believe that their health will be worse when they get older, they have a lower preferred retirement age. Looking at the point estimate for the total sample, individuals who strongly agree with this statement prefer to retire on average almost 6 years earlier than individuals who strongly disagree, holding the other variables constant. This relationship is also found when looking separately at men and women, and individuals with a low, middle, or high education.

For women only, the findings show that individuals who consider themselves old want to retire earlier (in support of $\mathrm{H} 1 \mathrm{~b}$ ). Women who strongly disagree with the statement "I don't consider myself to be old" want to retire on average more than 4 years earlier than women who strongly agree with this statement, holding the other variables constant. Surprisingly, women who agree with the statement "My age prevents me from doing the things I would like to do" want to retire later than women who disagree with this statement (contradicting $\mathrm{H} 1 \mathrm{a}$ ).

Thus far, results from qualitative research indicating that health pessimism may negatively affect when individuals want to retire is confirmed. Also, it is found that more general age perceptions (such as perceiving oneself to be old) may be negatively related to when one wants to retire, but only for women. A large benefit of quantitative analyses is that one can see to what degree these relationships hold when controlling for other factors, such as one's actual current health.

\subsection{With Controls}

Worry that one's health will worsen with age remains negatively related to one's preferred retirement age, but only significantly for women (see Table 3 ). The effect has become less strong, but still, women who strongly agree with the statement prefer to retire on average about 3 years earlier than women who strongly disagree with the statement, holding all other variables constant. When separating it out by gender and educational level, this seems to be mainly driven by (low and) middleeducated women $\left(b_{\text {women }}+\right.$ low education $=-0.85[-2.85$; 0.62], $\mathrm{n}=99 ; \mathrm{b}_{\text {women }+ \text { mid education }}=-0.88[-1.88$; $-0.33], \mathrm{n}=172 ; \mathrm{b}_{\text {women }}+$ high education $=-0.17[-1.05$; $0.57], n=104)$. For men, this relationship was not significant and, if existent, most likely to exist among highly educated men $\left(b_{\text {men }}+\right.$ low education $=0.04[-1.76 ; 1.22]$, $\mathrm{n}=98 ; \mathrm{b}_{\text {men }}+$ mid education $=-0.06[-0.80 ; 0.87], \mathrm{n}=108$;

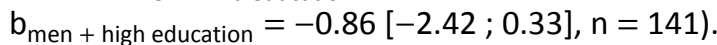

For middle-educated women, considering oneself to be old was also significantly and negatively related to preferred retirement age $\left(b_{\text {women }}+\right.$ low education $=-0.02$ $[-1.25 ; 0.96], \mathrm{n}=99 ; \mathrm{b}_{\text {women }}+$ mid education $=-0.43$ $[-0.93 ;-0.03], n=172 ; b_{\text {women }}+$ high education $=-0.04$ $[-0.74 ; 0.67], \mathrm{n}=104)$. For men, the point estimate of the relationship is only negative for lowly educated men, not for middle and highly educated men $\left(b_{\text {men }}+\right.$ low education $=-0.18[-1.26 ; 1.02], \mathrm{n}=98$; $\mathrm{b}_{\text {men }+ \text { mid education }}=0.19[-0.61 ; 1.45], \mathrm{n}=108$;

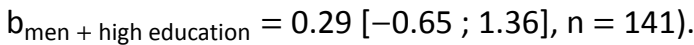

Thinking that "Old age is a time of ill health" (the more generalised form of health pessimism) and that "My age prevents me from doing the things I would like to do" were not significantly related to preferred retirement age in any of the models.

In sum, I have found no evidence for H1a: "Believing that (old) age limits activities is negatively related to one's preferred retirement age". In the analysis without controls, this relationship is, if existing, positive rather than negative, and this relationship disappears in the analysis with control variables. I have found some support for H1b: "Perceiving oneself to be old is negatively related to one's preferred retirement age". This relationship appears to exist for women only, and in the analysis with control variables, only for middle-educated women. This corresponds with my theoretical framework where it was argued that it is most likely to find the relationships for middle-educated individuals and women. Finally, most support is found for $\mathrm{H} 2$ : "Health pessimism is negatively related to one's preferred retirement age". Specifically, the belief that one's own health will decrease when getting old is negatively related to one's preferred retirement age. This relationship appears to be (again) most pronounced for middle-educated women.

\subsection{Robustness Checks}

For the tables indicating the robustness checks, please see the Annex. First, I assessed the preferred retirement age in wave 7 instead of 8 to verify whether the two-year gap between the waves makes us miss relationships (i.e., is the two-year gap too long?). It could, for example, be that individuals have changed their opinion regarding the statement that old age is a time of ill health (e.g., because a friend or relative got seriously ill) within the two-year timeframe and that the respondent has also changed his or her preferred retirement age because of this. In general, it does not appear to be the case that important relationships are missed by the modelling strategy. Worrying that one's health will get worse when the respondent is older is still the statement most clearly related to one's preferred retirement age. In wave 7 , I find one additional relationship for the full sample; age prevents is positively related to preferred retirement age. When splitting out by educational level, this appears to be driven by middleeducated individuals (see Table A1 in the Annex). When control variables are added, there are also some small differences in the findings. In wave 7, thinks old is negatively related to preferred retirement age for women 
Table 2. Regression preferred retirement age wave 8, without controls.

\begin{tabular}{|c|c|c|c|c|c|c|c|c|c|c|c|c|c|c|c|c|c|c|}
\hline \multirow[b]{2}{*}{ Variables } & \multicolumn{3}{|c|}{ Total sample } & \multicolumn{3}{|c|}{ Men only } & \multicolumn{3}{|c|}{ Women only } & \multicolumn{3}{|c|}{ Low education only } & \multicolumn{3}{|c|}{ Middle education only } & \multicolumn{3}{|c|}{ High education only } \\
\hline & $b$ & $L L$ & $U L$ & $b$ & $L L$ & $U L$ & $b$ & $L L$ & $U L$ & $b$ & $L L$ & $U L$ & $b$ & $L L$ & $U L$ & $b$ & $L L$ & $U L$ \\
\hline Thinks old & -0.32 & -0.69 & 0.16 & 0.31 & -0.31 & 1.11 & -0.84 & -1.28 & -0.43 & -0.40 & -1.17 & 0.38 & -0.48 & -1.00 & 0.34 & 0.11 & -0.64 & 0.89 \\
\hline Old bad health & 0.14 & -0.32 & 0.58 & -0.00 & -0.77 & 0.57 & 0.15 & -0.41 & 0.77 & 0.31 & -0.64 & 1.31 & 0.03 & -0.70 & 0.59 & -0.05 & -0.90 & 0.60 \\
\hline Worry old health & -1.15 & -1.71 & -0.67 & -1.13 & -1.96 & -0.42 & -1.01 & -1.78 & -0.39 & -1.59 & -2.90 & -0.59 & -0.90 & -1.62 & -0.34 & -1.13 & -2.36 & -0.23 \\
\hline Age prevents & 0.44 & -0.09 & 0.96 & 0.07 & -0.77 & 0.86 & 0.73 & 0.04 & 1.47 & 0.00 & -1.10 & 1.19 & 0.55 & -0.14 & 1.26 & 0.63 & -0.25 & 1.55 \\
\hline Constant & 67.62 & 66.08 & 69.67 & 67.98 & 65.61 & 71.23 & 67.11 & 65.13 & 69.56 & 70.40 & 66.84 & 74.74 & 66.65 & 64.54 & 69.44 & 66.89 & 64.19 & 70.76 \\
\hline $\mathrm{R}^{2}$ & 0.03 & & & 0.04 & & & 0.05 & & & 0.05 & & & 0.05 & & & 0.03 & & \\
\hline $\mathrm{N}$ & 722 & & & 347 & & & 375 & & & 197 & & & 280 & & & 245 & & \\
\hline
\end{tabular}

Notes: Confidence intervals are bias-corrected and accelerated confidence intervals, based on 5000 bootstrapped samples; LL = Lower Limit; UL = Upper Limit. 
Table 3. Regression preferred retirement age wave 8, with controls

\begin{tabular}{|c|c|c|c|c|c|c|c|c|c|c|c|c|c|c|c|c|c|c|}
\hline \multirow[b]{2}{*}{ Variables (wave 7) } & \multicolumn{3}{|c|}{ Total sample } & \multicolumn{3}{|c|}{ Men only } & \multicolumn{3}{|c|}{ Women only } & \multicolumn{3}{|c|}{ Low education only } & \multicolumn{3}{|c|}{ Middle education only } & \multicolumn{3}{|c|}{ High education only } \\
\hline & $b$ & $L L$ & $U L$ & $b$ & $L L$ & $U L$ & $b$ & $L L$ & $U L$ & $b$ & $L L$ & $U L$ & $b$ & $L L$ & $U L$ & $b$ & $L L$ & $U L$ \\
\hline Thinks old & -0.10 & -0.39 & 0.24 & 0.09 & -0.42 & 0.68 & -0.24 & -0.61 & 0.11 & -0.19 & -0.90 & 0.51 & -0.23 & -0.62 & 0.32 & 0.10 & -0.41 & 0.71 \\
\hline Old bad health & -0.00 & -0.35 & 0.34 & -0.18 & -0.74 & 0.28 & 0.13 & -0.31 & 0.61 & 0.37 & -0.41 & 1.24 & -0.09 & -0.67 & 0.37 & -0.31 & -0.94 & 0.22 \\
\hline Worry old health & -0.41 & -0.86 & -0.01 & -0.21 & -0.95 & 0.38 & -0.60 & -1.29 & -0.14 & -0.33 & -1.63 & 0.62 & -0.47 & -1.05 & 0.01 & -0.47 & -1.42 & 0.18 \\
\hline Age prevents & -0.10 & -0.55 & 0.31 & -0.24 & -0.94 & 0.39 & 0.04 & -0.54 & 0.66 & -0.94 & -1.95 & -0.05 & 0.25 & -0.33 & 0.87 & 0.37 & -0.29 & 1.14 \\
\hline $\begin{array}{l}\text { Self-rated health } \\
\text { No illness (ref) }\end{array}$ & 0.17 & -0.26 & 0.65 & 0.42 & -0.23 & 1.19 & 0.00 & -0.61 & 0.65 & 0.47 & -0.52 & 1.77 & -0.33 & -0.94 & 0.34 & 0.40 & -0.21 & 1.14 \\
\hline Illness & 0.44 & -0.30 & 1.34 & -0.01 & -1.08 & 1.07 & 0.87 & -0.26 & 2.29 & 1.23 & -0.23 & 3.27 & 0.42 & -0.62 & 1.97 & -0.22 & -1.55 & 1.13 \\
\hline $\begin{array}{l}\text { Activity limiting illness } \\
\text { Income quartile } 1 \text { (lowest) (ref) }\end{array}$ & -1.03 & -2.08 & 0.15 & 0.13 & -1.53 & 2.28 & -1.97 & -3.36 & -0.75 & -1.40 & -3.94 & 1.80 & -1.40 & -2.83 & -0.10 & -1.49 & -3.30 & 0.09 \\
\hline Income quartile 2 & -0.06 & -1.32 & 1.11 & 0.49 & -1.29 & 2.41 & -0.54 & -2.43 & 0.92 & 1.08 & -1.53 & 3.28 & -1.74 & -3.68 & -0.39 & 1.25 & -0.77 & 3.58 \\
\hline Income quartile 3 & -0.09 & -1.37 & 1.04 & -0.10 & -1.77 & 1.53 & 0.14 & -1.73 & 1.66 & 0.56 & -2.22 & 2.96 & -1.17 & -2.93 & 0.41 & 0.81 & -1.15 & 2.43 \\
\hline Income quartile 4 (highest) & -0.77 & -2.02 & 0.38 & -0.41 & -2.06 & 1.25 & -1.11 & -3.00 & 0.46 & -0.50 & -3.23 & 2.17 & -2.05 & -3.93 & -0.77 & 0.56 & -1.47 & 2.34 \\
\hline Fulltime job (vs. part-time) & -0.41 & -1.34 & 0.39 & -1.58 & -3.92 & 0.14 & 0.12 & -0.92 & 0.98 & 0.33 & -1.95 & 2.44 & -0.58 & -1.86 & 0.36 & -0.85 & -2.98 & 0.49 \\
\hline Age & 0.79 & 0.69 & 0.89 & 0.75 & 0.63 & 0.89 & 0.79 & 0.65 & 0.92 & 0.92 & 0.71 & 1.16 & 0.61 & 0.51 & 0.75 & 0.88 & 0.69 & 1.05 \\
\hline $\begin{array}{l}\text { Female (vs. male) } \\
\text { Low education (ref) }\end{array}$ & -0.72 & -1.49 & 0.02 & - & - & - & - & - & - & -0.08 & -1.81 & 1.90 & -1.29 & -2.65 & -0.32 & -0.77 & -1.92 & 0.37 \\
\hline Middle education & -0.51 & -1.47 & 0.32 & -0.44 & -1.82 & 0.79 & -0.70 & -2.04 & 0.45 & - & - & - & - & - & - & - & - & - \\
\hline High education & -0.59 & -1.57 & 0.37 & -0.59 & -1.98 & 0.66 & -0.67 & -2.11 & 0.73 & - & - & - & - & - & - & - & - & - \\
\hline Constant & 21.33 & 14.81 & 27.61 & 23.24 & 14.28 & 31.06 & 21.42 & 12.51 & 30.13 & 11.58 & -5.34 & 25.17 & 34.19 & 26.60 & 41.14 & 13.76 & 2.72 & 25.52 \\
\hline$R^{2}$ & 0.40 & & & 0.40 & & & 0.41 & & & 0.38 & & & 0.41 & & & 0.48 & & \\
\hline $\mathrm{N}$ & 722 & & & 347 & & & 375 & & & 197 & & & 280 & & & 245 & & \\
\hline
\end{tabular}

Notes: Confidence intervals are bias-corrected and accelerated confidence intervals, based on 5000 bootstrapped samples; LL = Lower Limit; UL = Upper Limit. 
while in wave 8 it is not, but the point estimate is -0.28 in wave 7 and $-0,23$ in wave 8 , not suggesting a large difference. Similarly, in wave 7 the coefficient is significant for the middle-educated, while it is not in wave 8 , but the point estimate is actually larger in wave 8 (wave $7:-0.43$; wave 8 : -0.47$)$. In wave 8 it is only significant for middleeducated women. Surprisingly, the coefficient of worry old health is less strong and not significant in wave 7 for women, while it is for wave 8 in the total sample and for women only. In wave 7, this is only significant for middleeducation women (see Table A2).

Second, I assessed what happened if the preferred retirement age was not truncated. Without control variables, results were the same in terms of which relationships were significant (see Table A3). With control variables, the impact of middle-educated women increased, making the overall relationship of considering oneself to be old for women significant as well (which was not the case when truncated). However, when splitting the sample by educational level, it is still only significant for middle-educated women (see Table A4).

Finally, the missing data were imputed to see to what degree missing data affected the results. These intervals were calculated on each individual imputed dataset because bias-corrected and accelerated confidence intervals cannot be combined with multiple imputations. The combined results, as well as the times the corrected confidence intervals did not include zero, can be found in Table A5 in the Annex. Without control variables, worry old health was not significantly related to preferred retirement age in any of the imputed datasets for highereducated only. The positive relationship between age prevents and preferred retirement age for women only was smaller and no longer significant. With control variables, worry old health was only significantly and negatively related to preferred retirement age in all imputed datasets for middle-educated women.

To conclude, the robustness checks show some differences with the main analyses. However, the following conclusions remain: most evidence appears to be for the relationship worry old health and preferred retirement age. This relationship is mostly found for middleeducated women. For lower or middle-educated women (but not higher-educated women) there also appears to be a (negative) relationship between considering oneself to be old and preferred retirement age. For men, there is less evidence that age perceptions affect the preferred retirement age.

\section{Conclusion}

Age discrimination is mentioned as possibly hindering the extending working lives agenda (see e.g., Loretto \& White, 2006; Walker \& Maltby, 2012). The impact of ageism may be larger than actively blocking individuals from certain jobs, however. It has been suggested that internalised ageism affects individuals' expectations and behaviours (Levy, 2009). This article assessed the degree to which considering oneself to be old, health pessimism, and agreeing that age prevents the respondent from doing the things they would like to do is related to their preferred retirement age two years later. It found that health pessimism is indeed related to a lower preferred retirement age. This corresponds with qualitative research on health pessimism (see, e.g., Brown \& Vickerstaff, 2011; Pond et al., 2010). This may be because individuals want to "maximise their enjoyment of their remaining years of good health" and expect to be in worse health later on, therefore they want to retire now (Pond et al., 2010, p. 533). However, it may also be that work is physically very demanding meaning they cannot see how one could continue to work in older age (Lain et al., in press).

For women only, it was also found that considering oneself to be old was negatively related to the preferred retirement age. This is controlled for health pessimism. This suggests that it is not only about health. Other old age beliefs may therefore also affect women's retirement planning. This corresponds with the qualitative study of Van der Horst (2018) which showed that individuals had internalised various (positive and negative) views on what it means to be old and that this affected their retirement planning.

I did not find that believing that age limits activities negatively affected the preferred retirement age. Without control variables, this relationship was even positive. It may be that some individuals want to stop working, but their age and financial situation does not allow them to retire yet, leading them to agree that age limits activities and mention high preferred retirement ages. When controlling for age and other factors, this relationship then disappears. It is also unclear how individuals interpreted this question as it may be a measure of the quality of life, experienced age discrimination, and/or internalised views on what is age-appropriate (also see Section 2.2 on internalised ageism).

These findings underline the importance of using an intersectionality lens in the field of work (cf. Crenshaw, 1989; McBride, Hebson, \& Holgate, 2015). Ageism will not be uniformly experienced by everyone of the same or similar age, nor will the consequences be the same. It relates, among others, to gender and educational level. For example, specifically regarding ageism and sexism, it has been claimed that:

Women's experiences with ageism are often gendered, that women's experiences with sexism are often intertwined with age, and that these intersections occur even when individuals categorize their mistreatment in terms of a single system of inequality. (Harnois, 2015, p. 102)

In this article, the focus is on (internalised) ageism, but it is acknowledged that this will be experienced differently and will have different effects for various groups of older workers. With ageism being gendered (e.g., Duncan \& 
Loretto, 2004; Radl, 2012) and classed (e.g., Palmore, 2001; Radl, 2012), it was suggested that women and lower educated individuals were more likely to experience ageism. With lower educated people being more likely to be in a situation where they are financially dependent on their work in older age, it was suggested that middle-educated people would be especially affected by (internalised) age stereotypes. At the same time, women are expected to retire at younger ages than men (Radl, 2012), perhaps making it more acceptable for women than for men to exclude themselves from the labour market at earlier ages. These processes may occur at the same time, and relationships indeed appear to be most clear for middle-educated women. Future research should unpack these relationships further.

It should be noted that the current article assessed preferred retirement age and even though this is considered a predictor of actual retirement age, it is by no means a perfect predictor (see, e.g., Solem et al., 2016). Preferred retirement age is relevant in its own right as it shows when individuals (say they) want to retire, but it should be kept in mind that this does not mean that individuals will actually retire at this age. They may retire earlier or later based on a variety of factors, such as being made redundant, financial feasibility, and/or health shocks. Future research may want to wait until there are more waves of ELSA to assess when individuals will actually retire and relate this to internalised ageism. The current time availability ( 2 years) is considered too short to properly assess these relationships using these data. Further, although preferred retirement age does not have to be 'self-exclusion' but instead could, for example, be setting oneself free for pursuits outside of the workforce, it is assumed in this article that the degree to which it relates to age perceptions is likely to be related to self-exclusion. This interpretation also fits the 'socioeconomics' perspective and the stereotype embodiment theory described in the theoretical background and with qualitative literature indicating that these perceptions may relate to excluding oneself from certain situations (see, e.g., Minichiello et al., 2000; Pond et al., 2010). Nevertheless, it is important to study this mechanism in greater detail in further research.

The sample studied in this article may be biased as it only contains 'survivors' in the labour market. To be included in the sample, they needed to be in paid labour. Individuals who already exited the labour market were not included. This could lead to an underestimation of the effect of internalised ageism on preferred retirement age as individuals most affected may have already left the labour market. Future research may want to assess this further.

Future research should also assess various pathways in which these relationships could work. For example, now, models are controlled for health. However, Levy (2009) shows that internalised ageism also affects health expectations and behaviour and may have health consequences. I may be underestimating the effect of inter- nalised ageism on preferred retirement age in the controlled model if health is a mediator rather than a control variable. These relationships should be teased out further in future research.

It would be useful, based on the claim that age stereotypes differ for various groups of workers (cf. Radl, 2012), if future research assessed the specific stereotypes in various jobs, the retirement preferences associated with these stereotypes, and the relationship between internalised ageism and preferred retirement age as well as retirement behaviour within these jobs. This would give a more detailed view of how internalised ageism relates to self-exclusion from the labour market. This would also help assess to what degree the differences between men and women and educational levels are due to actual gendered and classed ageism, or due to vertical and horizontal segregation on the labour market. Moreover, other intersections with age should be theorised and explored as well, such as based on ethnicity and/or disability (cf. McBride et al., 2015).

Despite these limitations and suggestions for future research, it is important to realise that the impact of ageism on labour market behaviour may go beyond discrimination alone. Circumventing ageist stereotypes may, therefore, be important to stimulate older workers to extend their working lives. It would also help if companies are more inclusive for individuals with various (dis)abilities. This is not to say that individuals should always continue working (see also Lain et al., in press), but if individuals would see that working with disabilities is a genuine option, they may be more likely to want to continue working regardless of their (future) (possible) disabilities. However, this may also involve addressing (dis)ableism more generally, because if the main reason individuals are affected by health pessimism is that they want to enjoy the remaining years of good health and, thus, assume that having less good health means one cannot enjoy oneself, 'just' having more inclusive workplaces will not be enough.

\section{Acknowledgments}

The author would like to thank David Lain and Marian Duggan, the editors of this thematic issue Wouter De Tavernier and Marja Aartsen, and three anonymous reviewers for their help on previous versions of this article.

\section{Conflict of Interests}

The author declares no conflict of interests.

\section{References}

Ahmed, A. M., Andersson, L., \& Hammarstedt, M. (2012). Does age matter for employability? A field experiment on ageism in the Swedish labour market. $A p$ plied Economics Letters, 19, 403-406. https://doi. org/10.1080/13504851.2011.581199 
Azulai, A. (2014). Ageism and future cohorts of elderly: Implications for social work. Journal of Social Work Values and Ethics, 11, 2-12. Retrieved from http:// jswve.org/download/2014-2/articles/2-JSWVE-112-Ageism-and-future-Cohorts-of-Elderly.pdf

Bjursell, C., Nystedt, P., Björklund, A., \& Sternäng, O. (2017). Education level explains participation in work and education later in life. Educational Gerontology, 43, 511-521. https://doi.org/10.1080/ 03601277.2017 .1357397

Brown, P., \& Vickerstaff, S. (2011). Health subjectivities and labor market participation: Pessimism and older workers' attitudes and narratives around retirement in the United Kingdom. Research on Aging, 33(5), 529-550. https://doi.org/10.1177/ 0164027511410249

Crenshaw, K. (1989). Demarginalizing the intersection of race and sex: A black feminist critique of antidiscrimination doctrine, feminist theory and antiracist politics. University of Chicago Legal Forum, 1989(1), 139-167.

Duncan, C., \& Loretto, W. (2004). Never the right age? Gender and age-based discrimination in employment. Gender, Work and Organization, 11, 95-115. https://doi.org/10.1111/j.1468-0432.2004.00222.x

Egdell, V., Maclean, G., Reaside, R., \& Chen, T. (2018). Age management in the workplace: Manager and older worker accounts of policy and practice. Ageing \& Society. https://doi.org/10.1017/ S0144686X18001307

Etzioni, A. (2000). Social norms: Internalization, persuasion, and history. Law \& Society Review, 34, 157-178. https://doi.org/10.2307/3115119

Grendon, T. L., Inker, J., \& Welleford, A. (2018). “How old do you feel?" The difficulties and ethics of operationalizing subjective age. Gerontologist, 58(4), 618-624. https://doi.org/10.1093/geront/gnx098

Harnois, C. E. (2015). Age and gender discrimination: Intersecting inequalities across the lifecourse. At the Center: Feminism, Social Science and Knowledge, 20, 85-109. https://doi.org/10.1108/S1529212620150000020005

ILC-UK. (2017). Exploring retirement transitions: A research report from ILC-UK and the Uncertain Futures Consortium. London: ILC-UK. Retrieved from https://ilcuk.org.uk/wp-content/uploads/2018/10/ Exploring_Retirement_Transitions.pdf

Jyrkinen, M., \& McKie, L. (2012). Gender age and ageism: Experiences of women managers in Finland and Scotland. Work, Employment and Society, 26, 61-77. https://doi.org/10.1177/0950017011426313

Lain, D., Van der Horst, M., \& Vickerstaff, S. (in press). Extending working lives: Feasible \& desirable for all? In S. J. Czaja, J. James, J. Grosch, \& J. Sharit (Eds.), Current and emerging trends in aging and work. New York, NY: Springer Publishing.

Levy, B. (2009). Stereotype embodiment: A psychosocial approach to aging. Current Directions in Psycholog- ical Science, 18, 332-336. https://doi.org/10.1111/ j.1467-8721.2009.01662.x

Loretto, W., \& Vickerstaff, S. (2013). The domestic and gendered context of retirement. Human Relations, 66, 65-86. https://doi.org/10.1177/ 0018726712455832

Loretto, W., \& White, P. (2006). Employers' attitudes, practices and policies towards older workers. Human Resource Management Journal, 16, 313-330. https://doi.org/10.1111/j.1748-8583.2006.00013.x

Marmot, M., Oldfield, Z., Clemens, S., Blake, M., Phelps, A., Nazroo, J., . . . Oskala, A. (2018). English Iongitudinal study of ageing: Waves 0-8, 1998-2017 [data collection]. UK Data Service. Retrieved from https://beta.ukdataservice.ac.uk/datacatalogue/ doi/?id=5050\#!\#15

Maurer, T. J., Barbeite, F. G., Weiss, E. M., \& Lippstreu, M. (2008). New measures of stereotypical beliefs about older workers' ability and desire for development: Exploration among employees age 40 and over. Journal of Managerial Psychology, 23, 395-418. https:// doi.org/10.1108/02683940810869024

McBride, A., Hebson, G., \& Holgate, J. (2015). Intersectionality: Are we taking enough notice in the field of work and employment relations. Work, Employment and Society, 29(2), 331-341. https://doi.org/ 10.1177/0950017014538337

Minichiello, V., Browne, J., \& Kendig, H. (2000). Perceptions and consequences of ageism: Views of older people. Ageing and Society, 20, 253-278.

Ng, T. W. H., \& Feldman, D. C. (2012). Evaluating six common stereotypes about older workers with metaanalytical data. Personnel Psychology, 65, 924-858. https://doi.org/10.1111/peps.12003

O'Connor, J. S., Orloff, A. S., \& Shaver, S. (1999). States, markets, families: Gender, liveralism and social policy in Australia, Canada, Great Britain and the United States. Cambridge: Cambridge University Press.

Palmore, E. (2001). The ageism survey: First findings. The Gerontologist, 41, 572-575. https://doi.org/10. 1093/geront/41.5.572

Phillipson, C. (2018). 'Fuller' or 'extended' working lives? Critical perspectives on changing transitions from work to retirement. Ageing \& Society. https://doi. org/10.1017/S0144686X18000016

Pond, R., Stephens, C., \& Alpass, F. (2010). How health affects retirement decisions: Three pathways taken by middle-older aged New Zealanders. Ageing \& Society, 30, 527-545. https://doi.org/10.1017/ S0144686X09990523

Posthuma, R. A., \& Campion, M. A. (2009). Age stereotypes in the workplace: Common stereotypes, moderators, and future research directions. Journal of Management, 35, 158-188. https://doi.org/10. $1177 / 0149206308318617$

Puth, M.-T., Neuhäuser, M., \& Ruxton, G. D. (2015). On the variety of methods for calculating confidence intervals by bootstrapping. Journal of Animal 
Ecology, 84, 892-897. https://doi.org/10.1111/13652656.12382

Radl, J. (2012). Too old to work, or too young to retire? The pervasiveness of age norms in Western Europe. Work, Employment and Society, 26, 755-771. https:// doi.org/10.1177/0950017012451644

Riach, P. A., \& Rich, J. (2002). Field experiments of discrimination in the market place. Economic Journal, 112, F480-F518.

Schulz, R., Noelker, L. S., Rockwood, K., \& Sprott, R. L. (2006). The encyclopaedia of aging (4th ed.). New York, NY: Springer Publishing.

Solem, P. E., Syse, A., Furunes, T., Mykletun, R.J., De Lange, A., Schaufeli, W., \& Ilmarinen, J. (2016). To leave or not to leave: Retirement intentions and retirement behaviour. Ageing and Society, 36, 259-281. https://doi.org/10.1017/S0144686X14001135

Statacorp. (2017). Stata statistical software: Release 15. College Station, TX: StataCorp LLC.

Swift, H. J., Abrams, D., Lamont, R. A., \& Drury, L. (2017). The risk of the ageism model: How ageism and nega- tive attitudes towards age can be a barrier to active ageing. Social Issues and Policy Reviews, 11, 195-231. https://doi.org/10.1111/sipr.12031

Van der Horst, M. (2018). Does internalised ageism result in self-exclusion in the United Kingdom? Manuscript submitted for publication.

Van der Horst, M., Lain, D., Vickerstaff, S., Clark, C., \& Geiger, B. B. (2017). Gender roles and employment pathways of older women and men in England. SAGE Open. https://doi.org/10.1177/2158244017742690

Walker, A., \& Maltby, T. (2012). Active ageing: A strategic policy solution to demographic ageing in Europe. International Journal of Social Welfare, 21, S117-S130. https://doi.org/10.1111/j.1468-2397.2012.00871.x

Wiggins, R. D., Netuveli, G., Hyde, M., Higgs, P. I., \& Blane, D. (2008). The evaluation of a self-enumerated Scale of Quality of Life (CASP-19) in the context of research on ageing: A combination of exploratory and confirmatory approaches. Social Indicators Research, 89, 61-88. https://doi.org/10.1007/s11205-007-9220-5

\section{About the Author}

Mariska van der Horst is Lecturer (Universitair Docent/Assistant Professor) at the VU Amsterdam, the Netherlands. The main focus of her research is on labour market issues, with a particular interest in older workers, gender differences, disability, and intersectionality. She published in a variety of journals, such as Human Relations, Social Indicators Research, and Sociological Research Online. For more information and to stay up to date on her research, please visit her website at http://mariskavanderhorst.com 
Annex

Table A1. Preferred retirement age wave 7.

\begin{tabular}{|c|c|c|c|c|c|c|c|c|c|c|c|c|c|c|c|c|c|c|}
\hline \multirow[b]{2}{*}{ Variables } & \multicolumn{3}{|c|}{ Total sample } & \multicolumn{3}{|c|}{ Men only } & \multicolumn{3}{|c|}{ Women only } & \multicolumn{3}{|c|}{ Low education only } & \multicolumn{3}{|c|}{ Middle education only } & \multicolumn{3}{|c|}{ High education only } \\
\hline & $b$ & $L L$ & $U L$ & $b$ & $L L$ & $U L$ & $b$ & $L L$ & $U L$ & $b$ & $L L$ & $U L$ & $b$ & $L L$ & $U L$ & $b$ & $L L$ & $U L$ \\
\hline Thinks old & -0.28 & -0.56 & 0.03 & 0.12 & -0.26 & 0.74 & -0.63 & -0.97 & -0.32 & -0.30 & -0.91 & 0.20 & -0.38 & -0.77 & 0.26 & -0.14 & -0.61 & 0.32 \\
\hline Old bad health & 0.15 & -0.15 & 0.43 & 0.32 & -0.19 & 0.75 & -0.09 & -0.44 & 0.27 & 0.29 & -0.21 & 0.80 & -0.06 & -0.58 & 0.38 & 0.26 & -0.21 & 0.80 \\
\hline Worry old health & -0.70 & -1.02 & -0.39 & -0.62 & -1.10 & -0.14 & -0.67 & -1.07 & -0.25 & -0.91 & -1.54 & -0.24 & -0.56 & -0.98 & -0.17 & -0.70 & -1.34 & -0.04 \\
\hline Age prevents & 0.41 & 0.05 & 0.79 & 0.03 & -0.54 & 0.55 & 0.71 & 0.21 & 1.23 & -0.16 & -0.95 & 0.56 & 0.76 & 0.25 & 1.26 & 0.38 & -0.37 & 1.03 \\
\hline Constant & 65.27 & 64.26 & 66.28 & 65.20 & 63.56 & 66.69 & 65.23 & 63.96 & 66.54 & 67.35 & 65.49 & 69.73 & 64.58 & 63.18 & 65.91 & 64.60 & 62.67 & 66.53 \\
\hline $\mathrm{R}^{2}$ & 0.02 & & & 0.01 & & & 0.05 & & & 0.03 & & & 0.04 & & & 0.02 & & \\
\hline $\mathrm{N}$ & 1,067 & & & 497 & & & 570 & & & 284 & & & 415 & & & 368 & & \\
\hline
\end{tabular}

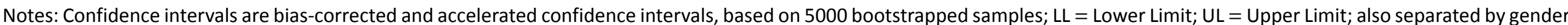

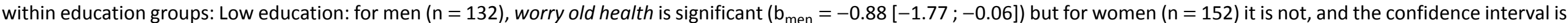

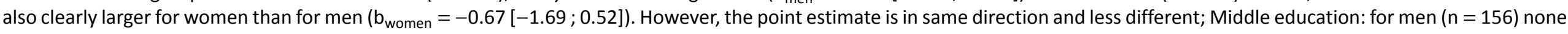

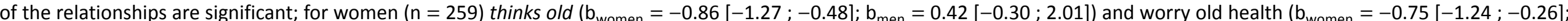

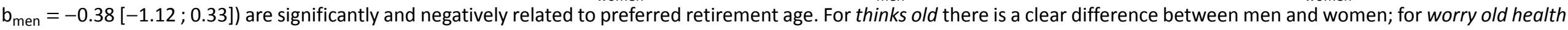

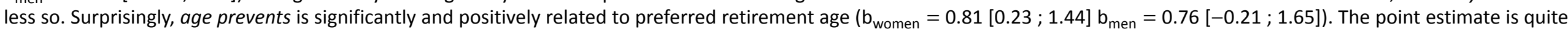
similar for men, but not significant due to a larger BCa confidence interval; High education: For men $(n=209)$ and women $(n=159)$ none of the relationships are significant. 
COGITATIO

Table A2. Preferred retirement age wave 7.

\begin{tabular}{|c|c|c|c|c|c|c|c|c|c|c|c|c|c|c|c|c|c|c|}
\hline \multirow[b]{2}{*}{ Variables } & \multicolumn{3}{|c|}{ Total sample } & \multicolumn{3}{|c|}{ Men only } & \multicolumn{3}{|c|}{ Women only } & \multicolumn{3}{|c|}{ Low education only } & \multicolumn{3}{|c|}{ Middle education only } & \multicolumn{3}{|c|}{ High education only } \\
\hline & $b$ & $L L$ & $U L$ & $b$ & $L L$ & $U L$ & $b$ & $L L$ & $U L$ & $b$ & $L L$ & $U L$ & $b$ & $L L$ & $U L$ & $b$ & $L L$ & $U L$ \\
\hline Thinks old & -0.13 & -0.37 & 0.12 & 0.08 & -0.25 & 0.54 & -0.28 & -0.64 & -0.00 & -0.10 & -0.74 & 0.40 & -0.17 & -0.48 & 0.29 & -0.15 & -0.51 & 0.22 \\
\hline Old bad health & 0.12 & -0.12 & 0.35 & 0.21 & -0.20 & 0.57 & 0.06 & -0.24 & 0.35 & 0.38 & -0.09 & 0.89 & -0.07 & -0.52 & 0.32 & 0.22 & -0.15 & 0.61 \\
\hline Worry old health & -0.26 & -0.52 & -0.00 & -0.16 & -0.54 & 0.28 & -0.32 & -0.64 & 0.02 & -0.00 & -0.57 & 0.59 & -0.43 & -0.78 & -0.06 & -0.28 & -0.72 & 0.21 \\
\hline Age prevents & -0.13 & -0.44 & 0.18 & -0.35 & -0.82 & 0.10 & -0.01 & -0.41 & 0.39 & -0.88 & -1.56 & -0.28 & 0.41 & -0.05 & 0.85 & -0.18 & -0.81 & 0.39 \\
\hline $\begin{array}{l}\text { Self-rated health } \\
\text { No illness (ref) }\end{array}$ & 0.10 & -0.20 & 0.43 & 0.12 & -0.34 & 0.69 & 0.11 & -0.24 & 0.50 & 0.77 & 0.15 & 1.56 & -0.17 & -0.63 & 0.43 & -0.04 & -0.51 & 0.38 \\
\hline Illness & 0.45 & -0.13 & 1.12 & 0.87 & -0.05 & 1.71 & 0.15 & -0.67 & 1.06 & 0.43 & -0.62 & 1.44 & 1.03 & 0.08 & 2.30 & 0.01 & -0.98 & 1.08 \\
\hline $\begin{array}{l}\text { Activity limiting illness } \\
\text { Income quartile } 1 \text { (lowest) (ref) }\end{array}$ & -0.58 & -1.30 & 0.13 & -0.18 & -1.22 & 0.90 & -0.83 & -1.86 & 0.09 & -1.05 & -2.53 & 0.45 & -1.01 & -2.25 & 0.05 & -0.02 & -1.16 & 1.04 \\
\hline Income quartile 2 & -0.04 & -0.90 & 0.80 & 0.42 & -0.90 & 2.01 & -0.36 & -1.54 & 0.65 & 0.06 & -1.52 & 1.41 & -0.32 & -1.89 & 0.96 & 0.57 & -0.99 & 2.09 \\
\hline Income quartile 3 & 0.10 & -0.79 & 0.89 & 0.17 & -1.03 & 1.57 & 0.04 & -1.13 & 1.08 & 0.78 & -0.67 & 2.34 & -0.58 & -1.97 & 0.69 & 0.68 & -0.57 & 1.92 \\
\hline Income quartile 4 (highest) & -0.42 & -1.31 & 0.39 & -0.36 & -1.56 & 1.00 & -0.53 & -1.72 & 0.42 & 0.23 & -1.13 & 1.68 & -0.95 & -2.45 & 0.30 & 0.13 & -1.13 & 1.37 \\
\hline Fulltime job (vs part-time) & -0.36 & -0.89 & 0.18 & -0.28 & -1.37 & 0.69 & -0.36 & -0.95 & 0.24 & -0.56 & -1.77 & 0.73 & -0.54 & -1.38 & 0.21 & 0.16 & -0.66 & 1.01 \\
\hline Age & 0.59 & 0.53 & 0.66 & 0.57 & 0.48 & 0.68 & 0.60 & 0.52 & 0.68 & 0.69 & 0.56 & 0.84 & 0.46 & 0.39 & 0.56 & 0.69 & 0.58 & 0.82 \\
\hline $\begin{array}{l}\text { Female (vs male) } \\
\text { Low education (ref) }\end{array}$ & -1.00 & -1.52 & -0.48 & - & - & - & - & - & - & -1.18 & -2.34 & 0.09 & -0.62 & -1.51 & 0.23 & -1.16 & -1.98 & -0.39 \\
\hline Middle education & 0.06 & -0.58 & 0.68 & -0.47 & -1.49 & 0.42 & 0.35 & -0.47 & 1.27 & - & - & - & - & - & - & - & - & 一 \\
\hline High education & -0.40 & -1.08 & 0.26 & -0.24 & -1.31 & 0.63 & -0.60 & -1.51 & 0.29 & - & - & - & - & - & - & - & - & - \\
\hline Constant & 30.49 & 25.94 & 34.66 & 30.62 & 23.25 & 37.14 & 29.74 & 24.11 & 35.09 & 22.49 & 11.91 & 31.83 & 38.94 & 33.43 & 44.17 & 23.92 & 15.96 & 31.53 \\
\hline $\mathrm{R}^{-}$ & 0.36 & & & 0.32 & & & 0.38 & & & 0.37 & & & 0.32 & & & 0.45 & & \\
\hline $\mathrm{N}$ & 1,067 & & & 497 & & & 570 & & & 284 & & & 415 & & & 368 & & \\
\hline
\end{tabular}

Notes: Confidence intervals are bias-corrected and accelerated confidence intervals, based on 5000 bootstrapped samples; LL = Lower Limit; UL = Upper Limit; also separated by gender within education groups: Low education: for men $\left(n=132, n_{\text {bootstrap }}=5,000\right)$ none of the relationships are significant; for women $\left(n=152, n_{\text {bootstrap }}=5,000\right)$, age prevents is significantly and negatively related to preferred retirement age $\left(b_{\text {women }}=-1.13[-2.18 ;-0.32] ; b_{\text {men }}=-0.73[-1.45 ; 0.09]\right)$. Relationship seems to be somewhat stronger for women than men, but for men also negative relationship and only just insignificant; Middle education: For men $\left(n=156 ; n_{\text {bootstrap }}=5,000\right)$ none of the relationships are significant; for women $\left(n=259, n_{\text {bootstrap }}=5,000\right)$, thinks old $\left(b_{\text {women }}=-0.41[-0.74 ;-0.10] ; b_{\text {men }}=0.32[-0.38 ; 1.48]\right)$ and worry old health $\left(b_{\text {women }}=-0.60[-1.01 ;-0.18] ; b_{\text {men }}=-0.19[-0.86 ; 0.43]\right)$ are both negatively related to age retirement. Thinks old point estimate for men is positive, for worry old health it is negative, but less strong than for women; High education: For men $\left(n=209 ; n_{\text {bootstrap }}=5,000\right)$ age prevents is significantly and negatively related to preferred retirement age; for women $\left(b=159 ; n_{\text {bootstrap }}=5,000\right)$ it is not $\left(b_{\text {women }}=0.49[-0.25 ; 1.22]\right.$; $\left.\mathrm{b}_{\text {men }}=-0.85[-1.76 ;-0.14]\right)$. This relationship seems to only exist for men. 


\section{COGITATIO}

Table A3. Preferred retirement age wave 8 (not truncated/no control variables).

\begin{tabular}{|c|c|c|c|c|c|c|c|c|c|c|c|c|c|c|c|c|c|c|}
\hline \multirow[b]{2}{*}{ Variables } & \multicolumn{3}{|c|}{ Total sample } & \multicolumn{3}{|c|}{ Men only } & \multicolumn{3}{|c|}{ Women only } & \multicolumn{3}{|c|}{ Low education only } & \multicolumn{3}{|c|}{ Middle education only } & \multicolumn{3}{|c|}{ High education only } \\
\hline & $b$ & $L L$ & $U L$ & $b$ & $L L$ & $U L$ & $b$ & $L L$ & $U L$ & $b$ & $L L$ & $U L$ & $b$ & $L L$ & $U L$ & $b$ & $L L$ & $U L$ \\
\hline Thinks old & -0.62 & -1.29 & 0.05 & 0.24 & -0.72 & 1.45 & -1.33 & -2.38 & -0.69 & -1.14 & -2.96 & 0.12 & -0.61 & -1.37 & 0.54 & 0.10 & -1.02 & 1.05 \\
\hline Old bad health & 0.06 & -0.69 & 0.79 & -0.11 & -1.27 & 0.72 & 0.06 & -0.97 & 1.21 & 0.29 & -1.38 & 2.41 & -0.13 & -1.16 & 0.60 & -0.17 & -1.68 & 0.85 \\
\hline Worry old health & -1.59 & -2.52 & -0.88 & -1.47 & -2.80 & -0.52 & -1.54 & -3.13 & -0.55 & -2.52 & -4.86 & -0.94 & -1.16 & -2.77 & -0.45 & -1.48 & -3.64 & -0.20 \\
\hline Age prevents & 0.58 & -0.26 & 1.50 & -0.19 & -1.55 & 0.98 & 1.20 & 0.15 & 2.64 & 0.40 & -1.68 & 2.75 & 0.55 & -0.33 & 1.59 & 0.59 & -0.89 & 1.70 \\
\hline Constant & 69.94 & 69.46 & 73.60 & 70.39 & 66.68 & 77.03 & 69.39 & 66.37 & 74.59 & 74.46 & 68.52 & 83.04 & 68.26 & 65.28 & 74.30 & 68.91 & 64.95 & 77.14 \\
\hline$R^{2}$ & 0.03 & & & 0.03 & & & 0.04 & & & 0.04 & & & 0.04 & & & 0.02 & & \\
\hline $\mathrm{N}$ & 722 & & & 347 & & & 375 & & & 197 & & & 280 & & & 245 & & \\
\hline
\end{tabular}

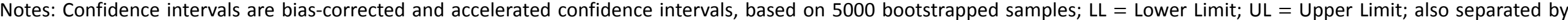

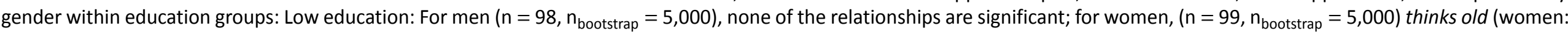

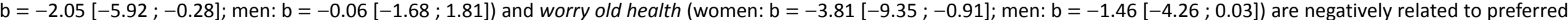

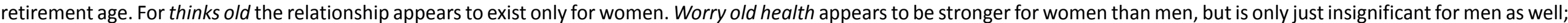

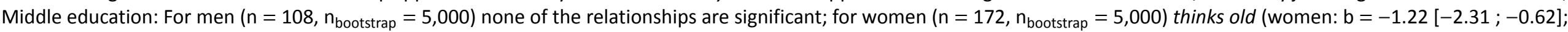

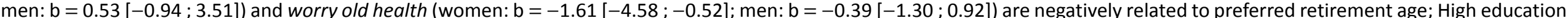

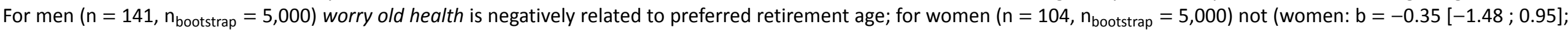
men: $b=-2.55[-6.09 ;-0.29])$. So this appears to be opposite compared to low and middle educ. 
Table A4. Preferred retirement age wave 8 (not truncated).

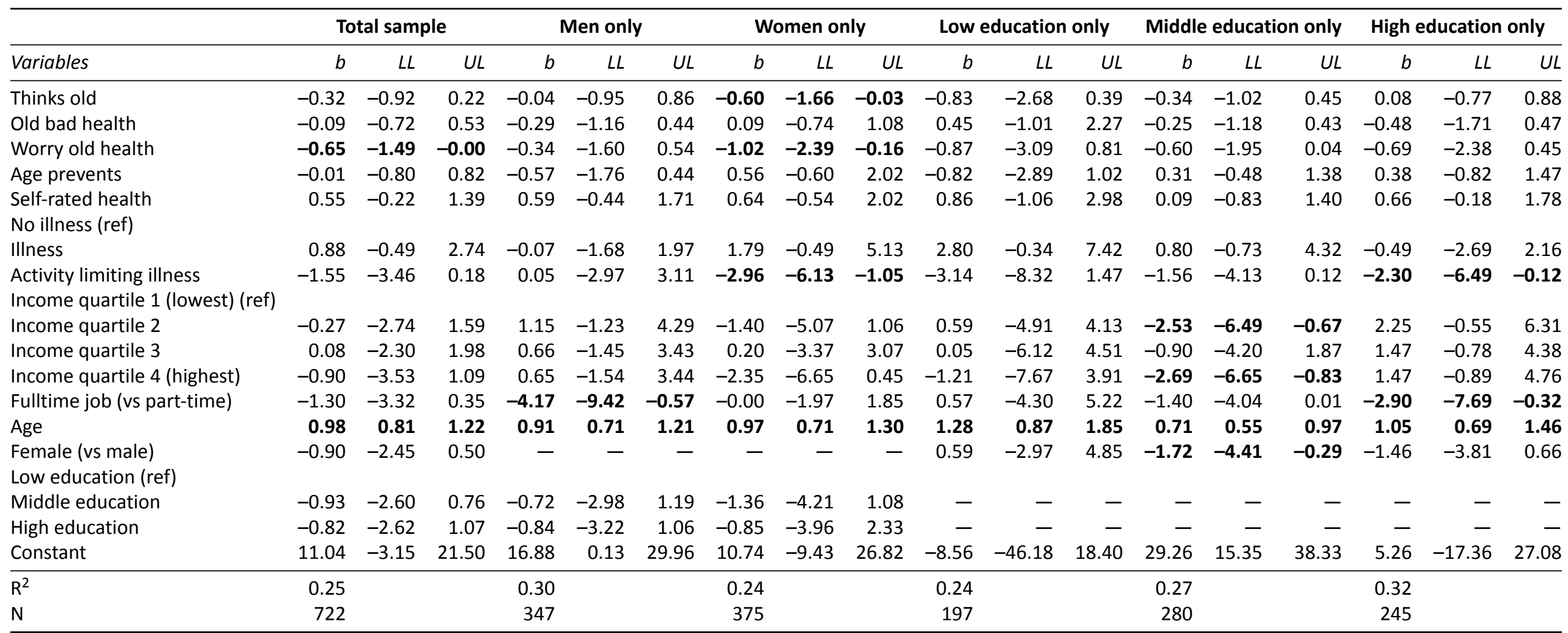

Notes: Confidence intervals are bias-corrected and accelerated confidence intervals, based on 5000 bootstrapped samples; LL = Lower Limit; UL = Upper Limit; also separated by gender within education groups: Low education: For men $\left(n=98, n_{\text {boostrap }}=4,999\right)$ and women $\left(n=99, n_{\text {bootstrap }}=5,000\right)$ none of the relationships are significant. Middle education: For men $\left(n=108, n_{\text {bootstrap }}=5,000\right)$ none of the relationships are significant; for women $\left(n=172, n_{\text {bootstrap }}=5,000\right)$ thinks old (women: $b=-0.65[-1.62 ;-0.13] ;$ men: $\left.b=0.18[-0.98 ; 2.04]\right)$ and worry old health (women $b=-1.21[-3.71 ;-0.38]$; men: $b=0.16[-0.75 ; 1.67]$ ) are negatively and significantly related to preferred retirement age. These negative associations only seem to exist for women (point estimate is positive for men). High education: For men $\left(n=141, n_{\text {bootstrap }}=5,000\right)$ and women $\left(n=104 ; n_{\text {bootstrap }}=4,988\right)$ none of the relationships are significant. 
COgITATIO

Table A5. Preferred retirement age wave 8 (multiple imputation).

\begin{tabular}{|c|c|c|c|c|c|c|c|c|c|c|c|c|c|c|c|c|c|c|}
\hline \multirow[b]{2}{*}{ Variables } & \multicolumn{3}{|c|}{ Total sample } & \multicolumn{3}{|c|}{ Men only } & \multicolumn{3}{|c|}{ Women only } & \multicolumn{3}{|c|}{ Low education only } & \multicolumn{3}{|c|}{ Middle education only } & \multicolumn{3}{|c|}{ High education only } \\
\hline & $b$ & $p$ & $\#$ sig & $b$ & $p$ & \# sig & $b$ & $p$ & \# sig & $b$ & $p$ & \# sig & $b$ & $p$ & \# sig & $b$ & $p$ & \# sig \\
\hline \multicolumn{19}{|l|}{ Without controls } \\
\hline Thinks old & -0.21 & .199 & 0 & 0.19 & .496 & 0 & -0.52 & .008 & 5 & -0.40 & .166 & 0 & -0.22 & .346 & 0 & -0.01 & .965 & 0 \\
\hline Old bad health & 0.03 & .880 & 0 & 0.02 & .936 & 0 & -0.04 & .871 & 0 & 0.16 & .660 & 0 & -0.04 & .878 & 0 & -0.07 & .827 & 0 \\
\hline Worry old health & -0.58 & .005 & 5 & -0.60 & .047 & 4 & -0.47 & .065 & 3 & -0.58 & .187 & 2 & -0.79 & .012 & 5 & -0.38 & .262 & 0 \\
\hline Age prevents & 0.25 & .239 & 0 & 0.10 & .754 & 0 & 0.35 & .214 & 0 & -0.36 & .375 & 0 & 0.51 & .119 & 1 & 0.40 & .286 & 0 \\
\hline \multicolumn{19}{|l|}{ With controls } \\
\hline Thinks old & -0.04 & .769 & 0 & 0.19 & .427 & 0 & -0.19 & .219 & 0 & -0.30 & .205 & 0 & 0.01 & .978 & 0 & 0.09 & .733 & 0 \\
\hline Old bad health & 0.03 & .829 & 0 & -0.03 & .888 & 0 & 0.10 & .601 & 0 & 0.33 & .265 & 0 & -0.09 & .661 & 0 & -0.15 & .558 & 0 \\
\hline Worry old health & -0.16 & .353 & 0 & -0.03 & .900 & 0 & -0.28 & .172 & 1 & -0.13 & .716 & 0 & -0.36 & .145 & 3 & -0.01 & .972 & 0 \\
\hline Age prevents & -0.22 & .212 & 0 & -0.16 & .548 & 0 & -0.26 & .252 & 0 & -0.84 & .015 & 5 & 0.04 & .878 & 0 & 0.01 & .966 & 0 \\
\hline $\mathrm{N}$ & 1,149 & & & 530 & & & 619 & & & 323 & & & 441 & & & 385 & & \\
\hline
\end{tabular}

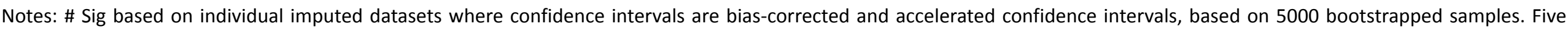

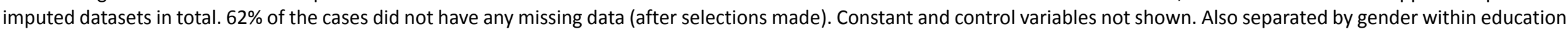

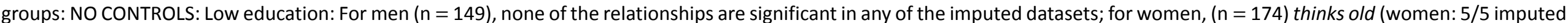

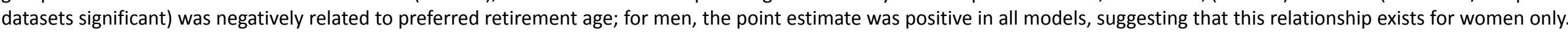

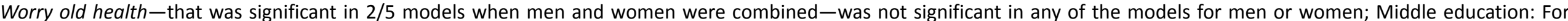

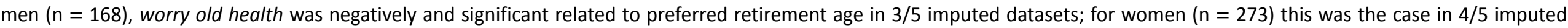

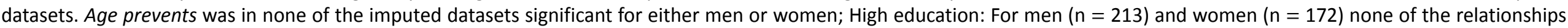

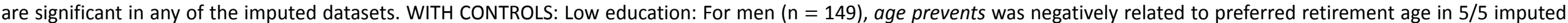

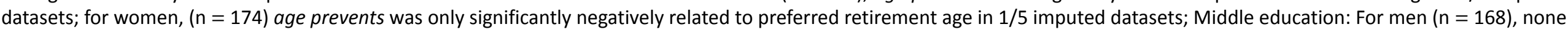

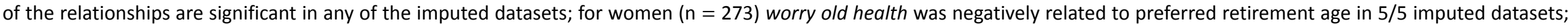
High education: For men $(n=213)$ and women $(n=172)$ none of the relationships are significant in any of the imputed datasets. 